\title{
Patient Rights: Awareness and Practice in a Tertiary Care Indian Hospital
}

\author{
${ }^{1}$ Alphonsa B Fernandes, ${ }^{2}$ Sweta D'Cunha, ${ }^{3}$ Sucharita Suresh
}

\section{ABSTRACT}

Aim and objectives: To study the awareness and practice of Patient rights and to compare the same between general and private ward hospitalized patients of a selected hospital.

Materials and methods: Descriptive research approach was adopted wherein data was collected from 120 hospitalized patients, i.e. 60 from general and 60 from private ward using a structured questionnaire. It was then analyzed by frequency, percentage and significance test to interpret the awareness and practice of patient rights in the hospital.

Results: The study reveals that awareness of patient rights was high in most of the cases. There was $71 \%$ awareness about the right to confidentiality, $67 \%$ awareness of the right to grievance redressal, $65 \%$ awareness about the right to be informed, $58 \%$ awareness of the right of access to healthcare and $55 \%$ awareness about the patient's right to choice of care and decision making. But low (39\%) awareness was noted in case of patient's right to informed consent.

With regards to practice of patient rights, it was seen that certain rights were well-practiced like $95 \%$ practice of the right of access to healthcare, $89 \%$ practice of the right to confidentiality and $64 \%$ practice of the right to choice of care and decision making. But relatively lower percentage of practice was observed for right to be informed (49\%), right to informed consent $(44 \%)$ and the right to grievance redressal $(21 \%)$. There was significant difference in the level of awareness and practice of patient rights among private and general ward patients in most of the rights.

Conclusion: The study was vital in finding that most respondents were aware of patient rights. So also, most of the patient rights were practiced in the hospital in varying degrees, while a few needed immediate rectification and management action.

Keywords: Patient rights, Awareness, Practice, Informed consent, Confidentiality.

How to cite this article: Fernandes AB, D'Cunha S, Suresh S. Patient Rights: Awareness and Practice in a Tertiary Care Indian Hospital. Int J Res Foundation Hosp Healthc Adm 2014;2(1):25-30.

\section{Source of support: Nil}

\section{Conflict of interest: None}

\author{
${ }^{1}$ Postgraduate Student, ${ }^{2}$ Associate Professor \\ ${ }^{3}$ Assistant Professor \\ ${ }^{1-3}$ Department of Hospital Administration, Father Muller Medical \\ College, Mangalore, Karnataka, India
}

Corresponding Author: Alphonsa B Fernandes, Postgraduate Student, Department of Hospital Administration, Father Muller Medical College, Kankanady, Mangalore-575002, Karnataka India, e-mail: alphonsa.fds@gmail.com,dsweeta@yahoo.com

\section{INTRODUCTION}

The World Health Organization, whose mission is to ensure 'health for all' and the Universal Declaration of Human Rights (1948), recognizes 'the inherent dignity' and the 'equal and unalienable rights of all members of the human family', and it is on the basis of this concept of the person, and the fundamental dignity and equality of all human beings, that the notion of patient rights was developed. In other words, what is owed to the patient as a human being, by physicians and by the state, took shape in large part thanks to this understanding of the basic rights of the person. ${ }^{1}$

According to a study of the New York Health Strategy Group, ${ }^{2}$ patients were very passive 30 years ago, but nowadays they are changing their attitude and becoming more health conscious and willing to make them heard. In view of this increasing gap between expectation and delivery of quality care, Patient rights have gained immense importance, especially for the purpose of statutory compliance in the field of medical practice. ${ }^{3}$ The recognition and promotion of patients' rights has been enhanced by various factors, such as special reforms of some health systems, the continuing progress of medical science and biomedical technology, the turning of society to values arising from fundamental human rights, the important changes occurring in the doctor-patient relationship, and the simplification and popularization of medical knowledge, made accessible to people mainly through the mass media.

According to SK Joshi, ${ }^{4}$ 'When we talk of the rights of a patient, we talk about the rights of a human being who is sick and suffering and needs help. It means his right to be provided the right kind of medical treatment by the right professionals at the right time using the right tools and techniques, with respect and human dignity, without any discrimination of any kind and much more than that. It means accountability of the providers for ensuring all the above in terms of the laid down norms and standards of quality.' As derived from above, patient rights are rights which may be classified as either legal, those emanating from law, or human statements of desirable principles, such as the right to healthcare/right to be treated with human dignity. ${ }^{5}$

Joshi further ${ }^{4}$ states that, 'In India, unlike in many other countries, the rights of patients have not yet been spelt out in a legal form. However, certain laws enacted from time- 
Table 1: Demographic details of the respondents

\begin{tabular}{|c|c|c|c|c|c|c|c|c|c|c|c|}
\hline \multicolumn{3}{|c|}{ Age total (120) } & \multicolumn{3}{|c|}{ Gender total (120) } & \multicolumn{3}{|c|}{ Educational qualification total (120) } & \multicolumn{3}{|c|}{ Occupation total (120) } \\
\hline Category & ${ }^{*} F$ & $\%$ & Category & ${ }^{*} F$ & $\%$ & Category & ${ }^{*} \mathrm{~F}$ & $\%$ & Category & ${ }^{*} F$ & $\%$ \\
\hline$<30$ years & 15 & 12.5 & Male & 51 & 42.5 & Illiterate & 23 & 19.16 & Laborer & 10 & 8.33 \\
\hline $31-45$ & 45 & 37.5 & Female & 69 & 57.5 & Primary & 36 & 30 & Skilled worker & 41 & 34.16 \\
\hline $46-60$ & 35 & 29.16 & & & & SSLC & 26 & 21.66 & Professional & 19 & 15.83 \\
\hline \multirow[t]{4}{*}{$>61$ years } & 25 & 20.83 & & & & PU & 14 & 11.66 & Retired & 8 & 6.66 \\
\hline & & & & & & Graduate & 12 & 10 & Student & 9 & 7.5 \\
\hline & & & & & & Postgraduate+ & 9 & 7.5 & Unemployed & 6 & 5 \\
\hline & & & & & & & & & Housewife & 27 & 22.5 \\
\hline
\end{tabular}

${ }^{*}$ Frequency

to-time and various judgments by the courts emanating from human rights, constitutional rights, civil rights, consumer rights and codes of ethics of medical and nursing profession have spelt out the obligations of the healthcare providers toward patients. This has, indirectly, conferred certain rights on the patients, such as the right of access to healthcare and to be treated with respect and dignity (IMC Regulations); the right to be informed (COPRA); the right to consent and choice of care (IMC Regulations); the right to privacy and confidentiality (IMC Regulations).'

The legal declaration of patient rights can be traced in the Consumer Protection Act, ${ }^{6}$ NABH Standards ${ }^{7}$ addressing the issue of Patient Rights in Chapter 4: patient rights and education (PRE) and the American Hospital Association: A Patient's Bill of Rights. ${ }^{8}$

Some of the basic, vital rights of patients are the right of access to healthcare with respect and dignity, the right to be informed, the right to confidentiality, the right to choice of care and decision making, right to informed consent and the right to redressal of grievances.

Research about patients' rights, the degree to which these rights are exercised and respected will reveal the existing situation for the care givers including healthcare administrators to help with the policy making and management of the services. Thus, the investigator wants to study the existing situation of the selected hospital so as to reaffirm the three (above stated) basic needs, paving a clear path toward statutory compliance and healthy patient caregiver relationship.

\section{MATERIALS AND METHODS}

A sample size of 120 hospitalized patients $(10 \%$ from the total number of patients admitted), i.e. 60 from general and 60 from private ward were selected using the convenience random sampling technique. A questionnaire was designed consisting of three parts - demographical data, awareness of patient rights and the practice of patient rights, etc. Awareness and practice was assessed using a 3 scale rating (agree, not sure, disagree) questionnaire. For analysis, rating of 'agree' is considered as aware/practiced and rating of 'not sure and disagree' is considered not aware/not practiced.
The collected data was then analyzed in terms of frequency and percentage. Mannwhitney test and chi-square test was done. Item wise analysis of each right was done and then compared for private and general ward patients respectively. The data was presented in the tabular form with all the essential statistical values.

\section{RESULT AND DISCUSSION}

\section{Demographic Details (Table 1)}

Demographic data of respondents reveals that majority belonged to the age group ranging 30 to 45 years. Majority of the respondents were female and with primary education and employed as skilled workers.

\section{Awareness of Patient Rights (Table 2)}

Most of the respondents were aware of the meaning of patient rights $(76 \%)$ and its goal $(73 \%)$. But very few $(43 \%)$ knew that it was applicable in India irrespective of the absence of a legal bill or charter. There was significant difference between private and general ward respondents and general wards respondents showing very low awareness (44\%).

A study conducted by Fehime Zülfikar, M Filiz Ulusoy ${ }^{9}$ revealed that only $23 \%$ of the participants were able to recognize patient rights, while $32 \%$ could not and the majority $(45 \%)$ was undecided in recognizing patient rights. So also, Koula Merakou et a ${ }^{10}$ found that $97.5 \%$ patients were not aware of the provision of patient rights. In comparison, this study has shown more awareness among patients on the concept of patient rights with respect to its meaning, goal and applicability.

Regarding the Right of Access to healthcare with respect and dignity; most $(90 \%)$ respondents were aware that they could not be physically or verbally abused by hospital staff nor could be discriminated on any grounds during their stay $(80 \%)$. But respondents rated low $(31 \%)$ in awareness regarding access to their medical records as most did not know that they had a right to have complete knowledge and explanation of their records if they so desired.

Respondents did not have much awareness regarding their right to be informed as almost half of the subjects did 
Patient Rights: Awareness and Practice in a Tertiary Care Indian Hospital

\begin{tabular}{|c|c|c|c|c|c|c|c|c|c|}
\hline \multirow{2}{*}{ Patient rights } & \multicolumn{2}{|c|}{ Total (120) } & \multicolumn{2}{|c|}{ Private } & \multicolumn{2}{|c|}{ General } & \multirow[t]{2}{*}{ Z-value } & \multirow[t]{2}{*}{${ }^{* *} p$-value } & \multirow[t]{2}{*}{$S$} \\
\hline & ${ }^{*} \mathrm{~F}$ & $\%$ & $\bar{F}$ & $\%$ & $\bar{F}$ & $\%$ & & & \\
\hline Meaning of patient rights & 92 & 76.66 & 57 & 95 & 35 & 58.33 & 4.7797 & $<0.0001$ & $S$ \\
\hline Goal of patient rights & 88 & 73.33 & 56 & 93.33 & 32 & 53.33 & 4.9349 & $<0.0001$ & S \\
\hline Applicability of patient rights & 52 & 43.33 & 39 & 65 & 13 & 21.66 & 4.8679 & $<0.0001$ & S \\
\hline $\begin{array}{l}\text { Awareness on the concept of } \\
\text { patient right }\end{array}$ & 77 & 64.44 & 50 & 84.44 & 27 & 44.44 & 4.5644 & $<0.0001$ & S \\
\hline Protection from physical/verbal abuse & 109 & 90.83 & 56 & 93.33 & 53 & 88.33 & 0.934 & 0.3503 & NS \\
\hline Access to medical records & 38 & 31.66 & 25 & 41.66 & 13 & 21.66 & 2.3686 & 0.0179 & $s$ \\
\hline Nondiscrimination & 97 & 80.83 & 55 & 91.66 & 42 & 70 & 2.9031 & 0.0037 & S \\
\hline $\begin{array}{l}\text { Awareness on right to access of } \\
\text { healthcare with respect } \& \text { dignity }\end{array}$ & 70 & 58.75 & 45 & 75.55 & 36 & 60 & 1.7541 & 0.0794 & S \\
\hline Information about illness & 102 & 85 & 58 & 96.66 & 44 & 73.33 & 3.4809 & 0.0005 & S \\
\hline Information on cost of treatment & 62 & 51.66 & 42 & 70 & 20 & 33.33 & 4.055 & $<0.0001$ & $S$ \\
\hline Information on research protocol & 70 & 58.33 & 51 & 85 & 19 & 31.66 & 5.9926 & $<0.0001$ & S \\
\hline Awareness on right to be informed & 78 & 65 & 50 & 83.88 & 28 & 46.11 & 4.2351 & $<0.0001$ & S \\
\hline Hospital/doctor/treatment choice & 83 & 69.16 & 56 & 93.33 & 27 & 45 & 5.6846 & $<0.0001$ & S \\
\hline Treatment alternative \& refusal & 51 & 42.5 & 36 & 60 & 15 & 25 & 3.8779 & 0.0001 & S \\
\hline Refuse/decline research protocol & 64 & 53.33 & 46 & 76.66 & 18 & 30 & 5.0481 & $<0.0001$ & S \\
\hline $\begin{array}{l}\text { Awareness on right to choice of care } \\
\text { and decision making }\end{array}$ & 66 & 55 & 46 & 76.66 & 20 & 33.33 & 4.7296 & $<0.0001$ & S \\
\hline Meaning of informed consent & 28 & 23.33 & 17 & 28.33 & 11 & 18.33 & 1.3015 & 0.1931 & NS \\
\hline Procedures requiring consent & 76 & 63.33 & 49 & 81.66 & 27 & 45 & 4.0841 & $<0.001$ & S \\
\hline Consent in emergency case & 40 & 33.33 & 25 & 41.66 & 15 & 25 & 1.8637 & 0.0624 & NS \\
\hline $\begin{array}{l}\text { Awareness on right to } \\
\text { informed consent }\end{array}$ & 47 & 39.31 & 30 & 50.55 & 18 & 29.44 & 2.3529 & 0.0186 & $\mathrm{~s}$ \\
\hline Confidentiality in patient information & 103 & 85.83 & 57 & 95 & 46 & 76.66 & 2.9556 & 0.0031 & S \\
\hline Privacy in examination \& treatment & 107 & 89.16 & 60 & 100 & 47 & 78.33 & 7.5032 & $<0.001$ & S \\
\hline Scope/extent of patient confidentiality & 46 & 38.33 & 31 & 51.66 & 15 & 25 & 2.9339 & 0.0033 & S \\
\hline $\begin{array}{l}\text { Awareness on patient's right to } \\
\text { confidentiality }\end{array}$ & 85 & 71.1 & 49 & 82.22 & 36 & 60 & 2.6556 & 0.0079 & S \\
\hline $\begin{array}{l}\text { Complain regarding } \\
\text { inconvenience faced }\end{array}$ & 94 & 78.33 & 59 & 98.33 & 35 & 58.33 & 5.2889 & $<0.0001$ & S \\
\hline File civil/consumer court case & 64 & 55.83 & 39 & 65 & 28 & 46.66 & 2.0941 & 0.0363 & S \\
\hline $\begin{array}{l}\text { Awareness on right to redressal } \\
\text { of grievances }\end{array}$ & 80 & 67.08 & 49 & 81.66 & 32 & 52.5 & 3.3653 & 0.0008 & S \\
\hline
\end{tabular}

${ }^{*} \mathrm{~F}$ denotes frequency; ${ }^{* *} p<0.05$ is significant and $p>0.05$ is nonsignificant; S: Significant; NS: Nonsignificant

not know that they had a right to know the treatment cost and also if there is any research protocol being practiced on them during their hospital stay (awareness @ 51 and 58\% respectively). This was especially so in the case of general ward respondents (awareness @ 33 and 31\% respectively).

A study conducted on Awareness and practice of patient's rights law in Lithuania ${ }^{11}$ disclosed that statistically large proportion of the patients $(69.0 \%)$ were aware of the statement that being informed about the diagnosis, medical treatment results and treatment methods was necessary. Additionally, Diagnosis and results of the medical examination were better understood, by 82 and $73 \%$ of the patients, respectively. In comparison to the above study, there is an equally high percentage of awareness on the right to information among patients of this selected hospital.
Awareness regarding right to choice of care and decision making was also very low (55\%) as it was seen that most respondents were not aware that they had a right to know the other treatment alternatives (only $42 \%$ were aware) and refuse care option suggested by their doctor if need be. So also very few $(53 \%)$ respondents were aware that they could refuse being part of any research or human experiment and even withdraw during the protocol if they felt the need to do so.

Most respondents showed very little awareness (39\%) regarding the right of informed consent where most of them did not even understand the meaning of an informed consent and others did not know that a consent was not needed in case of emergency treatments (only 23 and 33\% awareness respectively). Although $63 \%$ were aware of the common 


\begin{tabular}{|c|c|c|c|c|c|c|c|c|c|}
\hline \multirow[t]{2}{*}{ Patient rights } & \multicolumn{2}{|c|}{ Total (120) } & \multicolumn{2}{|c|}{ Private } & \multicolumn{2}{|c|}{ General } & \multirow[t]{2}{*}{ Z-value } & \multirow[t]{2}{*}{${ }^{* *} p$ value } & \multirow[t]{2}{*}{$S$} \\
\hline & ${ }^{*} F$ & $\%$ & ${ }^{*} F$ & $\%$ & ${ }^{*} F$ & $\%$ & & & \\
\hline Treated with respect and dignity & 111 & 92.5 & 57 & 95 & 54 & 90 & 1.0398 & 0.2985 & NS \\
\hline No gender/religion-based discrimination & 117 & 97.5 & 60 & 100 & 57 & 95 & -9.3229 & $<0.0001$ & S \\
\hline No discrimination on financial grounds & 115 & 95.83 & 60 & 100 & 55 & 91.66 & -8.8735 & $<0.0001$ & $\mathrm{~S}$ \\
\hline $\begin{array}{l}\text { Practice of right of access to healthcare } \\
\text { with respect and dignity }\end{array}$ & 114 & 95.27 & 59 & 98.33 & 55 & 92.22 & 1.5079 & 0.1316 & NS \\
\hline Information about illness and treatment & 82 & 68.33 & 47 & 78.33 & 35 & 58.33 & 2.3483 & 0.0189 & S \\
\hline Treatment cost well explained & 36 & 30 & 18 & 30 & 18 & 30 & 0 & 0.9999 & NS \\
\hline Practice of right to be informed & 59 & 49.16 & 33 & 54.16 & 27 & 44.16 & 1.0957 & 0.2732 & NS \\
\hline Patient choice and decision respected & 77 & 64.16 & 53 & 88.33 & 24 & 40 & 5.4772 & $<0.0001$ & $\mathrm{~S}$ \\
\hline $\begin{array}{l}\text { Practice of right to choice of care and } \\
\text { decision making }\end{array}$ & 77 & 64.16 & 53 & 88.33 & 24 & 40 & 5.4772 & $<0.0001$ & S \\
\hline Well informed consent & 53 & 44.16 & 42 & 70 & 11 & 18.33 & 5.7378 & $<0.0001$ & $S$ \\
\hline Practice of right to informed consent & 53 & 44.16 & 42 & 70 & 11 & 18.33 & 5.7378 & $<0.0001$ & $\mathrm{~S}$ \\
\hline Privacy in all procedures & 108 & 90 & 55 & 91.66 & 53 & 88.33 & 0.536 & 0.5919 & NS \\
\hline Patient and patient party privacy & 106 & 88.33 & 58 & 96.66 & 48 & 80 & 2.6968 & 0.007 & S \\
\hline Practice of right to confidentiality & 107 & 89.16 & 56 & 94.16 & 51 & 84.16 & 1.7505 & 0.08 & NS \\
\hline Grievance redressal system & 26 & 21.66 & 13 & 21.66 & 13 & 21.66 & 0 & 0.999 & NS \\
\hline $\begin{array}{l}\text { Practice of right to redressal of } \\
\text { grievances }\end{array}$ & 26 & 21.66 & 13 & 21.66 & 13 & 21.66 & 0 & 0.099 & NS \\
\hline Patient rights claim and provision & 96 & 80 & 53 & 88.33 & 43 & 71.66 & 2.3065 & 0.0211 & S \\
\hline Practice of rights claim and provision & 96 & 80 & 53 & 88.33 & 43 & 71.66 & 2.3065 & 0.0211 & S \\
\hline
\end{tabular}

${ }^{*} \mathrm{~F}$ denotes frequency; ${ }^{* *} p<0.05$ is significant and $p>0.05$ is nonsignificant; S: Significant; NS: Nonsignificant

procedures which required their consent but whether an informed one was still a doubt to them.

In comparison, a study on patients' perceptions of written consent ${ }^{12}$ revealed that most participants $(646,88 \%)$ believed it was a legal requisite to sign a consent form before surgery. Nearly a quarter $(169,23 \%)$ did not know whether the operation could be performed if they were unable to sign the consent form, even if non-intervention could result in their death (in cases of emergency), and $55(8 \%)$ mistakenly assumed it could not. Most patients (86\%) thought their signature confirmed that they understood what was going to happen to them, and that there are risks involved in having surgery $(82 \%)$.

In case of right to confidentiality, the respondents rated better (71\%) in awareness as most (89\%) of them were aware that they had the right to privacy during their examination and treatment and $85 \%$ were aware that their patient-related information had to be maintained confidentially in the hospital.

It was also interesting to observe that most (78\%) of the respondents were aware that they had the right to redress their grievances faced during their stay but only about $55 \%$ said that they could file a civil/consumer court case if necessary to redress their grievances.

A study carried out by Koula Merakou, Panagiota Dalla-Vorgia, Tina Garanis-Papadatos and Jeny KoureaKremastinou $^{10}$ found that one out of four patients (25.7\%) would do nothing if some of his or her rights were violated. Less than one-third (28.8\%) would make a complaint to the particular person responsible for the violation; $27.5 \%$ would complain to that person's superior; $13.3 \%$ would submit a written complaint to an administrative officer; and 3.5\% would appeal to a court.

There was significant difference in the level of awareness of private and general ward patients in almost all the rights presented. This may be a result of the varying level of educational qualification of the respondents in private and general wards. Although there was no significant difference in the awareness level between the two comparison groups with regards to the awareness on the right to access of healthcare without being physically or verbally abused during their stay. So also, there was no significant difference in case of the awareness regarding the meaning of Informed consent and the need for consent during an emergency. In these two cases, both the groups were found unaware and confused.

\section{Practice of Patient Rights (Table 3)}

With respect to the practice of patient rights, it was seen that the respondents felt that their right to access of healthcare with respect and dignity was highly practiced. With above $90 \%$ respondents saying that the staff treated them with respect and dignity and there was no discrimination on the grounds of gender, religion or finance. 
Patient Rights: Awareness and Practice in a Tertiary Care Indian Hospital

\begin{tabular}{|c|c|c|c|c|}
\hline \multirow[t]{2}{*}{ Patient rights } & \multicolumn{2}{|c|}{ Awareness (120) } & \multicolumn{2}{|c|}{ Practice (120) } \\
\hline & Frequency & $\%$ & Frequency & $\%$ \\
\hline Right of access to healthcare & 70 & 58.75 & 114 & 95.27 \\
\hline Right to be informed & 78 & 65 & 59 & 49.16 \\
\hline Right to choice and decision making & 66 & 55 & 77 & 64.16 \\
\hline Right to informed consent & 47 & 39.31 & 53 & 44.16 \\
\hline Right to confidentiality & 85 & 71.1 & 107 & 89.16 \\
\hline Right to redressal of grievances & 80 & 67.08 & 26 & 21.66 \\
\hline Overall & 72 & 59.88 & 76 & 63.33 \\
\hline
\end{tabular}

Most (68\%) respondents marked that they were informed of their illness and the treatment but very few (30\%) were well explained regarding the costs that were involved. This was same for both private as well as general ward patients. In comparison, a cross-sectional survey from a tertiary care hospital on the east coast of Peninsular Malaysia ${ }^{13}$ found that about $85 \%$ of patients felt that they were informed regarding their illness and modality of treatment; however, treatment options were discussed with only $45 \%$ of the cases and only $65 \%$ of patients were informed of the duration of their treatment.

Regarding the right to choice of care and decision making, it was seen that more than half (64\%) respondents felt that their choice/decision was respected and upheld at all times by the staff.

Unfortunately very few (44\%) responded that they had given an informed consent to the procedures related to their treatment. This was extremely less in case of general ward patients where only $18 \%$ had given an informed consent.

A study conducted by Andrea Akkad, Clare Jackson, Sara Kenyon, Mary Dixon-Woods, Nick Taub and Marwan Habiba $^{12}$ disclosed that many patients (71\%) agreed that the consent form made clear what was going to happen to them, and $77 \%$ reported that it made them aware of the risks of the operation they were to undergo. Compared to the above study, this is indeed a negative rate of practice. It must be noted that all had signed on the consent form but very few (the above stated percentage) were fully explained and informed of the consent.

Right to confidentiality was well practiced as most of the respondents rated practice of confidentiality and privacy during their procedures and stay above $85 \%$.

The hospital faired poorly with respect to the respondents' rating only $21 \%$ regarding the presence of a grievance redressal system in the hospital which is a right of the patient. This was true for both, private and general ward patients with no significant difference between the two.

But ironically, majority $(80 \%)$ of the respondents said that most of the rights were well-practiced and they feel confident enough to claim them in the hospital.
It was also noticed that there was significant difference in the practice and delivery of patient rights in case of private and general ward patients esp. with regards to the right to choice of care and decision making, right to informed consent and confidence in claiming once rights in the hospital where the general ward respondents expressed lesser rate of practice of these rights during their stay. This although has to be looked into carefully by the hospital authorities.

\section{Comparison between Rate of Awareness as against Practice (Table 4)}

As the rate of patient right awareness and its practice was compared, it can be seen that in most of the rights there was high awareness except the right to informed consent, while many rights were not satisfactorily practiced in the hospital like the patient's right to be informed, right to informed consent and the right to grievance redressal.

But some interesting conclusions may be drawn on the basis of the study: although awareness regarding patient's right of access to healthcare with respect and dignity was only $58 \%$, it was very well practiced at the rate of $95 \%$. The same applies to the right to confidentiality. But problem lies in other areas wherein the respondents are aware of their rights but these are not practiced well in the hospital according to the respondents. For example, the right to be informed (78\% as against $49 \%$ respectively), the right to choice of care and decision making (66\% as against $64 \%)$, right to informed consent (47\% as against $44 \%$ ) and the lowest being the right to grievance redressal (67\% as against $21 \%$ respectively).

\section{CONCLUSION}

The crux of this study was to find the level of awareness and practice of patient rights among hospitalized patients. There was high awareness about patient rights among the respondents except regarding the right to informed consent and right to choice of care and decision making. With regards to practice, some rights were not satisfactorily practiced in the hospital like the right to grievance redressal, 
right to informed consent and the patient's right to be informed.

There was significant difference noted in the level of awareness and practice between the private and general ward patients. Based on the analysis and findings, suggestions were made, which would result in the hospital being well-equipped in meeting any statutory compliance, fulfilling any accreditation criteria and providing qualitative patientcentered care.

\section{REFERENCES}

1. Available at: www.who.int/genomics/public/patientrights/en.

2. Fallberg LH. Patients' rights. European health care reforms: citizens' choice and patients' rights. Copenhagen: World Health Organization Regional Office for Europe 1996.p.11-20.

3. Ancona HD. Promotion of the rights of patients' in Europe. World Health Organization Regional Office for Europe. The Hague: Kluwer Law International 1995.p.1-6.

4. Joshi SK. Law and practice of medicine. First edition. New Delhi: Jaypee Brothers Medical Publishers (P) Ltd. 2010;266, 267,269-271.
5. Pozgar, George D. Legal aspects of healthcare administration. 8th ed. Massachusetts: Jones and Bartlett Publishers.p.322.

6. Available at: http://www.healthlibrary.com/book9.htm.

7. National Accreditation Board for Hospitals and Healthcare Providers. Guide book to NABH Standards for Hospitals. 2nd ed 2009;57-61.

8. Joint Commission on Accreditation of Healthcare Organizations. Ethical issues and patient rights: across the continuum of care. Publication, Joint Commission Resources 1998 Jan;1:24-25.

9. Zülfikar F, Ulusoy MF. Are patients aware of their rights? A Turkish study. Nurse Ethics 2001 Nov;8(6):487-498.

10. Merakou K, Dalla-Vorgia P, Garanis-Papadatos T, KoureaKremastinou J. Satisfying patients' rights: a hospital patient survey. Nursing Ethics 2001;8(6):p.4,6.

11. Ducinskiene D, Vladickiene J, Kalediene R, Haapala I. Awareness and practice of patient's rights law in Lithuania. BioMed Central Ltd Int 2006;6(10):3-4.

12. Akkad A, Jackson C, Kenyon S, Dixon-Woods M, Taub N, Habiba M. Patients' perceptions of written consent: questionnaire study. BMJ 2006;333:528.

13. Yousuf RM, Fauzi ARM, How SH, Akter SFU, Shah A. Hospitalised patients' awareness of their rights: a cross-sectional survey from a tertiary care hospital on the east coast of Peninsular Malaysia. Singapore Med J 2009;50(5):498. 